\title{
National and subnational experience with estimating the extent and trend in completeness of registration of deaths in Brazil ${ }^{1}$
}

\author{
Bernardo Lanza Queiroz \\ Universidade Federal de Minas Gerais \\ lanza@cedeplar.ufmg.br \\ Everton E. Campos de Lima \\ NEPO - Unicamp \\ everton@nepo.unicamp.br
}

\begin{abstract}
In this paper, we analyze the evolution of the completeness of death counts coverage in Brazil and its regions since 1980. We review a series of studies on the quality of mortality registration for the country, states and small areas, compare and contrast different approaches and results. We also investigate the quality of the 2010 Census data regarding the information on household deaths in 2010 to results obtained using the Ministry of Health Mortality Information System. Finally, we produce estimates at the city level and discuss the limitation and importance of producing small areas demographic estimation for public health planning and population forecasts.
\end{abstract}

Preliminary draft

Comments are welcome

\footnotetext{
${ }^{1}$ Research presented in this paper builds on collaborative work with Everton Lima (Unicamp), Flávio Freire (UFRN) and Marcos Gonzaga (UFRN). Support from the Research Projects 470866/2014-4 (MCTI/CNPQ/MEC/CAPES/Ciências Sociais Aplicadas) and 454223/2014-5 (MCTI/CNPQ/Universal 14/2014) are gratefully acknowledged.
} 


\section{Introduction}

The study of the pattern and level of mortality are very important in understanding the population dynamics, urban planning and social policies, especially at the local level. AbouZhar and Boerma (2005) argue that the appropriate decisions on public health occur only with appropriate information on health-related events; mortality, morbidity, causes of death; which require the existence of an adequate health information system. The basic pillar of this system is the correct recording of the number of deaths by age and sex in the country, but information on causes of death and disease are also critical to the development of appropriate policies. However, it is important to produce proper estimates of mortality at the national and subnational levels to subsidize the understanding of population dynamics.

In many countries, estimating mortality becomes a challenge, since the quality of information is generally unsatisfactory (Luy, 2010; Setel et.al, 2007). Advances in improving health information and mortality are increassing in recent decades and are observed even in less developed countries (Setel, et al, 2007), but there are still a large number of countries and regions within countries with restricted quality of mortality and health data. There are a number of demographic methods developed to estimate mortality at the different levels. Most important they provide a way perform an evaluation of the quality of mortality data (Brass, 1975; Preston et al., 1980; Bennett and Horiuchi, 1981; Hill, 1987; Hill and Timaeus Choi, 2005; Hill, You and Choi, 2009).

This paper reviews the evolution of completeness of registration of deaths in Brazil over the last few decades at different geographic levels. We present estimates of death counts under-reporting by sex and compare to estimates produced by other authors and agencies. We discuss the importance of evaluating data quality in Brazil in order to produce good mortality estimates and how demographic methods can be combined to statistical methods to produce small area estimates. Finally, we show some results of the evolution of adult mortality for small areas in Brazil.

In recent decades the quality of mortality data in Brazil showed significant progress, but with large regional variability (France et al, 2008; Agostinho, 2009; Agostinho and Queiroz, 2010). Lima and Queiroz (2014) showed the advancement of improved mortality information across Brazilian regions between 1980 and 2010. For Brazilian states, there are some studies time points that allow an analysis of the 
evolution of data quality. In particular, Paes (2005), Agostinho (2009) and Queiroz (2012) study the quality of mortality data from Brazilian states for the periods 19801991, 1991-2000 and 2000-2010 and show that there are signs of improvement but still a lot of regional heterogeneity. Thus, it is important to review all the estimates of completeness of death counts registration in Brazil and regions, analyze the main issues and limitations of methods and data and discuss the road ahead to keep improving the quality of mortality information in Brazil and regions in Latin America.

The results indicate the steady advance in the quality of mortality data in Brazil. In 2010, all the states of the South and Southeast regions have complete registration deaths and some located in the Northeast and Midwest. In addition, there was a breakthrough in the quality of mortality information in the poorer states of the Northeast and in the North, especially those who have the worst quality of the previous period. Regarding the mortality estimates for regions in Brazil, the results indicate an improvement in health conditions, as measured by the decline in the risk of death between ages 15 and 59. One point that draws attention and deserves further study is not reducing the difference in mortality between men and women in the last two decades.

\section{Data and Methods}

We use two sources of data for mortality in this paper. For the time trend analysis, we focus on the Ministry of Health Mortality Information System. We also perform some analysis using the 2010 Census data and compare, at the state level, information from census and Ministry of Health databases. One additional possibility, IBGE Vital Registration system will not be used in this paper; we follow the academic literature in Brazil and focus data analysis in the Ministry of Health Database.

\subsection{Ministry of Health - Mortality Information System}

We make extensive use of the Ministry of Health database, DATASUS (http://www2.datasus.gov.br). The database provides information on deaths, causes of deaths, by age and sex at the municipality level. The data are available since 1979, but we use information from 1980 to 2010 . Mortality data is organized using codes from the ICD Revision (9 $9^{\text {th }}$ from 1980 to 1995 and $10^{\text {th }}$ from 1996 on). Data cleaning and compilation is done at the municipal, provincial and state level, and an electronic data 
file is transferred to the national office every 3 months. Population by age and sex, at the local level, comes from the Brazilian Censuses (1980, 1991, 2000 and 2010).

\subsection{Population Census - 2010}

We use the information available in the Brazilian Census 2010 on the household deaths that occurred in the last 12 months. The respondent also informs sex and age of the person who died during the reference period. The inclusion of such information information is part of the suggestions made by the United Nations Principles and Recommendations for Population and Housing Censuses (1997) for the 2000 and 2010 census round. Household deaths should be evaluated very carefully because it is subject to four main problems: a) sub-enumeration of deaths due to breakage of households following the death of a resident or due to high concentration of residents in single person households; b) young people who migrate from their original homes can be registered as belonging to more than one domicile; c) errors in the reference period for that the definition of the period must be as clear as possible and d) possible random and significant fluctuations in mortality affecting the estimate of interest.

\subsection{Death Distribution Methods}

The demographic literature has developed several methods based upon equations of population dynamics to evaluate the coverage of reported deaths relative to populations. The death distribution methods (DDM) are commonly used to estimate adult mortality in a non-stable population. A stable population is one in which the birth and death rates are unchanging over a long period of time. The DDM methods compare the distribution of deaths by age with the age distribution of the living and provide age patterns of mortality in a defined reference period. There are two major approaches: the General Growth Balance Methods, and the Synthetic Extinct Generation method.

In this paper, we use the General Growth Balance method (GGB) and the Benneth Horichi Adjusted method. The method is derived from the basic demographic balancing equation, which expresses the identity that the growth rate of a population is equal to the difference between its entry rate and exit rate. Equation 1 shows the basic relations of the method

$$
\frac{N^{\prime}(x)}{N(x+)}-r^{\prime}(x+)=\frac{1}{t} \ln \left(\frac{k_{1}}{k_{2}}\right)+\frac{\left(k_{1} k_{2}\right)^{1 / 2}}{C}\left(\frac{D^{\prime}(x+)}{N(x+)}\right)
$$


Where $N^{\prime}(x)$ is the number of persons who reach the exact age $x$ in the period, $\mathrm{N}\left(\mathrm{x}^{+}\right)$is the number of persons at exact age $\mathrm{x}$ and over, $\mathrm{r}\left(\mathrm{x}^{+}\right)$is the population growth rate, $\mathrm{k} 1$ and $\mathrm{k} 2$ are the relative coverage of the enumerated population in two censuses, $\mathrm{C}$ is the degree of completeness of death records over the period, $\mathrm{D}^{\prime}\left(\mathrm{x}^{+}\right)$is the observed number of deaths of people with $\mathrm{x}$ or more years of age and $\mathrm{t}$ is the interval corresponding to the intercensal period

This identity holds for open-ended age segments $\mathrm{x}^{+}$, and in a closed population the only entries are through birthdays at age $\mathrm{x}$. The "birth" rate $\mathrm{x}+$ minus the growth rate $\mathrm{x}+$ thus provides a residual estimate of the death rate $\mathrm{x}+$. If the residual estimate can be calculated from population data from two population censuses and compared to a direct estimate using the recorded deaths, the completeness of death recording relative to population recording can be estimated. The method has a few strong and key assumptions: the population is closed to migration; the completeness of recording of deaths is constant by age; the completeness of recording of the population is constant by age; and ages of the living and dead are reported without error.

The death distribution method has also an important limitation. Since they compare a distribution of deaths to an intercensal population, they estimate intercensal completeness of mortality estimates, and not the completeness at the beginning or end of the intercensal period. This matter is of particular importance when a distribution of deaths comes from data from the latest census or when vital registration is available for recent years,. The assumption of the GGB method that the population is closed to migration is also of importance to Brazil and its regions. The GGB method uses information on deaths and growth rates cumulated above a series of ages $\mathrm{x}$. If there is some age $\mathrm{x}$ above which net migration is negligible, the performance of the methods above that age will be unaffected. The intercept and slope of the GGB method were obtained by orthogonal regression to points for the ages $35+$ to $75+$.

The Bennett and Horiuchi method, SEG, uses specific growth rates by age for converting an age distribution of deaths into an age distribution of a population. Once the observed deaths from a given age $\mathrm{x}$ in a population is equal to the population of age $\mathrm{x}$, adjusted by the rate of population growth by age range, we have the deaths of a population of age $\mathrm{x}+$ that provide an estimate of the population on that age $\mathrm{x}$. The extent of death registration coverage is given by the ratio of deaths estimated by the population 
above the age $\mathrm{x}$ and the observed population above the age $\mathrm{x}$. Equation 2 presents the mathematical formalization of the method

$$
N^{\prime}(x)=\sum_{a=x}^{\omega} D(a) e^{[r(a-r)]}
$$

Where $\mathrm{N}^{\prime}(\mathrm{x})$ is the number of people who reach the exact age $\mathrm{x}$ in a population with growth rate $r$, and $D(x)$ is the number of deaths at age $\mathrm{x}$. In this case, the estimate of deaths under-registration in the period is given by the ratio between the estimated number of people aged $x\left(N^{\prime}(x)\right)$ and the observed number of people aged $x(N(x))$. The diagnostic plot in this case should present a straight line across age, showing constant completeness. A change in the slope over the age groups indicates possible coverage problems of population censuses, problems in the age statement of the living and dead or variation in the quality of the registration / listing of deaths by age group

Hill and colleagues suggest that the combination of GGB and SEG methods may be more robust than the application of the two methods separately. The adjusted method consists of applying GGB to obtain estimates of the change in the population enumeration $(\mathrm{k} 1 / \mathrm{k} 2)$, and use this ratio to adjust the coverage of both census, and then apply the SEG method using the adjusted population for the coverage of mortality data.

\subsection{Problem with small numbers}

Knowing the exact level and structure of mortality is essential for government agencies to set up their health policies. In face of the millennium goals, more studies on this field are becoming necessary, especially when the population of interest is small. Such studies are important because they aid researchers investigating the environmental and behavioral aspects of diseases, the access to health care, and better understanding the socioeconomic determinants of mortality and morbidity in these areas (Ferguson et al.,2004).

Search for better estimates of rates in small areas gained ground in the research agenda of many demographers even with large samples and censuses, vital rates estimates in small areas are still very limited and incipient. This often happens due to the problem of few events recorded in the denominator and/or numerator of the 
measures of interest. This instability is even worse when sub-national groups are disaggregated by age and sex (Assunção et al. 2005). Bernadinelli and Montomoli (1992) argue that, in small populations, the estimated rates generally have extreme values, often dominated by sampling noise which less reflect the true risks. Assunção et al. (2005) also show that for a large number of small areas, one can observe a large variability in the estimated rates that do not reflect the true level of heterogeneity of the geographic location. Therefore, estimates of vital rates in small areas present a great challenge for demographers, but several authors argue that a variety of statistical methods exist to adequately address the volatility of these estimates (for example Ferguson, 2004). In studies estimating fertility rates in Brazil, Assunção et al. (2005) showed how Empirical Bayes was effective in the case of Brazilian municipalities. Therefore, estimates of vital rates in small areas present a great challenge for demographers, but several authors argue that a variety of statistical methods exist to adequately address the volatility of these estimates (for example Ferguson, 2004).

\section{Results}

\subsection{Evolution of Death Counts Coverage in Brazil}

\subsubsection{Evolution from 1980 to 2000}

Table 1 shows the trends in completeness of death counts coverage in Brazil, for males and females, using different methods and age ranges to estimate completeness and levels of adult mortality. Completeness improved systematically for the country since 1980, but with important differences between males and females. In general, completeness of death counts coverage is better for males than for females. The results indicate that coverage in Brazil increase, for males, from $84 \%$ in $1970-1980$ to $95 \%$ in 1991-2000, we will discuss 2000-2010 in detail later. For females, we find that completeness improved from $79 \%$ to $90 \%$. One important message from Table 1 is that different methods and different age ranges used to produce estimates can produce different results. Since the literature does not specify gold-standard method, it is important to present the results using different approaches. 
Table 1 - Completeness of death counts coverage, by sex and methods, Brazil, 1980-2000.

\begin{tabular}{l|r|r|r|r|r|r}
\hline \hline & \multicolumn{3}{|c|}{ Males } & \multicolumn{2}{|c}{ Females } \\
\hline Methods & $\mathbf{1 9 8 0}$ & $\mathbf{1 9 9 1}$ & $\mathbf{2 0 0 0}$ & $\mathbf{1 9 8 0}$ & $\mathbf{1 9 9 1}$ & $\mathbf{2 0 0 0}$ \\
Original Growth Balance & 0.806 & 0.879 & 0.873 & 0.745 & 0.775 & 0.796 \\
Preston and Coale & 0.859 & 0.912 & 0.949 & 0.809 & 0.878 & 0.906 \\
General Growth Balance & 1.142 & 0.981 & 1.022 & 1.222 & 0.992 & 1.028 \\
General Growth Balance Migration & 1.036 & 0.952 & 1.012 & 1.059 & 0.969 & 1.005 \\
Benneth-Horiuchi & 1.003 & 0.945 & 0.986 & 1.037 & 0.944 & 0.959 \\
Benneth-Horiuchi Adjusted & 1.089 & 0.946 & 0.958 & 1.138 & 0.951 & 0.953 \\
Average & $\mathbf{0 . 8 3 3}$ & $\mathbf{0 . 8 9 6}$ & $\mathbf{0 . 9 6 7}$ & $\mathbf{0 . 7 7 7}$ & $\mathbf{0 . 8 2 7}$ & $\mathbf{0 . 9 3 2}$ \\
\hline
\end{tabular}

Source: Agostinho and Queiroz (2010)

The importance of investigating data quality and performing necessary adjustments in the data is highlighted by the different levels in life expectancy one can obtain using observed data and adjusted data. For example, for males using observed data life expectancy at age 5 in 1980 is around 64 and in 2000 increased to 66.4 years. Using an average of the methods, we estimated e5 in 1980 in 61.8 years and 65.5 in 2000 .

\subsubsection{Situation in 2010 and comparison to household deaths from Census}

In Brazil, the Census 2010 gives a great opportunity to evaluate the mortality age profile in Brazil and compare to results obtained from the vital records system. Brazilian 2010 Census included in its questionnaire a question on household deaths between August 2009 and July 2010 and also information on age and sex of the deceased. Previously, the 1980 census included a question on deaths in the household in the sample questionnaire. However, to our knowledge, only Sawyer and Castilla (1989) made a systematic assessment of the quality of that information. The authors pointed out that despite having sub-list of issues the declaration of deaths the structure of mortality in five-year age groups, is fairly consistent and the data could serve as an important source for the study of adult mortality in the country. Regarding the degree of deaths enumeration coverage in the Census 1980, the authors find values ranging from $40 \%$ to annual data, $58 \%$ for information relating to the month preceding the Census.

Table 2 presents summary results, from Queiroz and Sawyer (2012), using different methods and an estimate of the probability of death among 15 and 60 years of age (45q15). Regarding the GGB, we present the intercept (which gives a measure of the two censuses coverage) and the slope that gives us the information for calculating 
the degree of coverage of mortality data. Queiroz and Swayer estimated completeness age intervals from $5+$ to $65+$ for the GGB method and $15+$ to $65+$ for the SEG method. The adult mortality estimates use completeness from the GGB method, but they poin that results are quite similar.

Tabela 2 - Completeness of Death Counts Coverage (SIM-Datasus) and Household Deaths (Census), 2010

\begin{tabular}{lcccc}
\hline & $\begin{array}{c}\text { Males } \\
\text { Census }\end{array}$ & $\begin{array}{c}\text { Males } \\
\text { SIM - Datasus }\end{array}$ & $\begin{array}{c}\text { Females } \\
\text { Census }\end{array}$ & $\begin{array}{c}\text { Females } \\
\text { SIM -Datasus }\end{array}$ \\
\hline GGB & & & & \\
$\quad \mathrm{k} 1 / \mathrm{k} 2$ & 0,9926 & 0,9919 & 0,9864 & 0,9890 \\
$\quad \begin{array}{c}\text { Completeness } \\
\text { SEG }\end{array}$ & 0,8575 & 0,9891 & 0,8106 & 0,9595 \\
$\quad \begin{array}{l}\text { Completeness } \\
\text { SEG ajustado }\end{array}$ & 0,8406 & 0,9724 & 0,8048 & 0,9431 \\
$\quad$ Completeness & 0,8137 & 0,9387 & & \\
$\quad \mathbf{4 5 q 1 5}$ & $\mathbf{0 , 2 1 3 2}$ & $\mathbf{0 , 2 1 1 1}$ & $\mathbf{0 , 1 1 6 4}$ & $\mathbf{0 , 1 0 5 6}$ \\
\hline
\end{tabular}

Source: Queiroz and Sawyer (2012)

Figure 1, obtained from Queiroz and Sawyer (2012), compares age-specific mortality rates (in log scale) for males, after adjustement, from census data and vital records. the male mortality rates derived from Census 2010 with the rates derived from SIM-DATASUS information. Age-specific mortality rates follow the expected pattern, there is an increased mortality rate with age and a bump for young adults. More importantly, the data obtained from the Census, as discussed above, allow perfectly capture the risk of mortality in young adult ages, usually by external causes, which is characteristic of the pattern of male mortality in Brazil. The over-mortality of young adults is observed both in the Census as SIM data, but Census somewhat over-estimates adult mortality.

Figura 1 - Age-Specific Mortality Rates Adjusted, SIM-Datasus and Census, Males, 2000-2010 


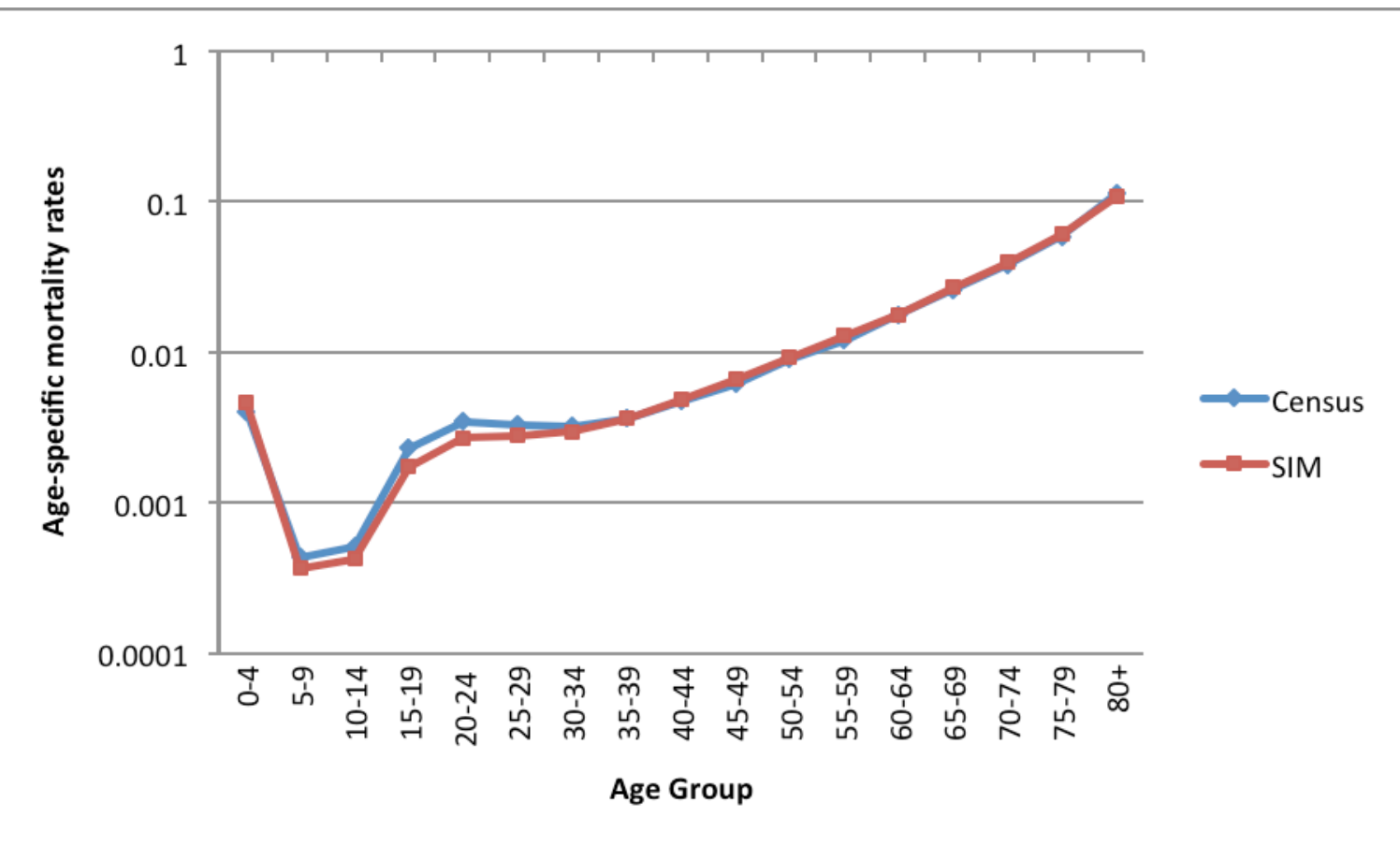

Source: Brazilian Population (2010) e SIM-Datasus (2010)

\subsubsection{An application of Wilmoth, et.al (2012)}

We perform a simple exercise to compare estimates age specific probabilities of death produced by IBGE (official estimates) to an application of Wilmoth et.al (2012) model life-table. The method does not produce an estimate of completeness of death counts coverage, but allows one to estimate full age profiles of mortality with limited or defective data.

Equation 1 formalizes the model:

$$
\log \left(m_{x}\right)=a_{x}+b_{x} h+c_{x} h^{2}+v_{x} k
$$

(Equation 1), where

$\log \left(\mathrm{m}_{\mathrm{x}}\right)$ is the age specific mortality rate,

$\mathrm{h}=\log \left({ }_{5} \mathrm{q}_{0}\right)$ reflects the level of child mortality,

$k$ reflects the level of excess adult mortality and is chosen to match ${ }_{45} q_{15}$ or other global measure of adult mortality, the other variables are constants in the model. In the application, $\mathrm{h}$ and $\mathrm{v}$ are the parameters we need to obtain a complete mortality age profile given the standards. 
The main disadvantage is that the constants in the model were constructed using countries in the Human Mortality Database and the experience of those countries might not reflect the experience of less developed countries. However, the method is very flexible and one could re-estimate the constants by adding other countries to the database. The main issue is that those additional countries might have data limitation and mortality age-profiles might have been estimated using indirect methods or model life-tables. Figure 2 compares the official estimates for Brazil in 2000 (IBGE) to the application of the log-quad model using one and two parameters. We use $5 \mathrm{q} 0$ and $45 \mathrm{q} 15$ from our estimates presented in the previous section. The main issue is the difference between the observed level in adult mortality by IBGE and using the log-quad methods. IBGE estimates $45 q 15$ in 0.2584 whereas one-parameter estimates is 0.2052 and twoparameter estimates is 0.2460 .

Figura 2 - Age specific probabilities of death between ages 15 and 60, 45q15, Males, Brazil, 2000. 


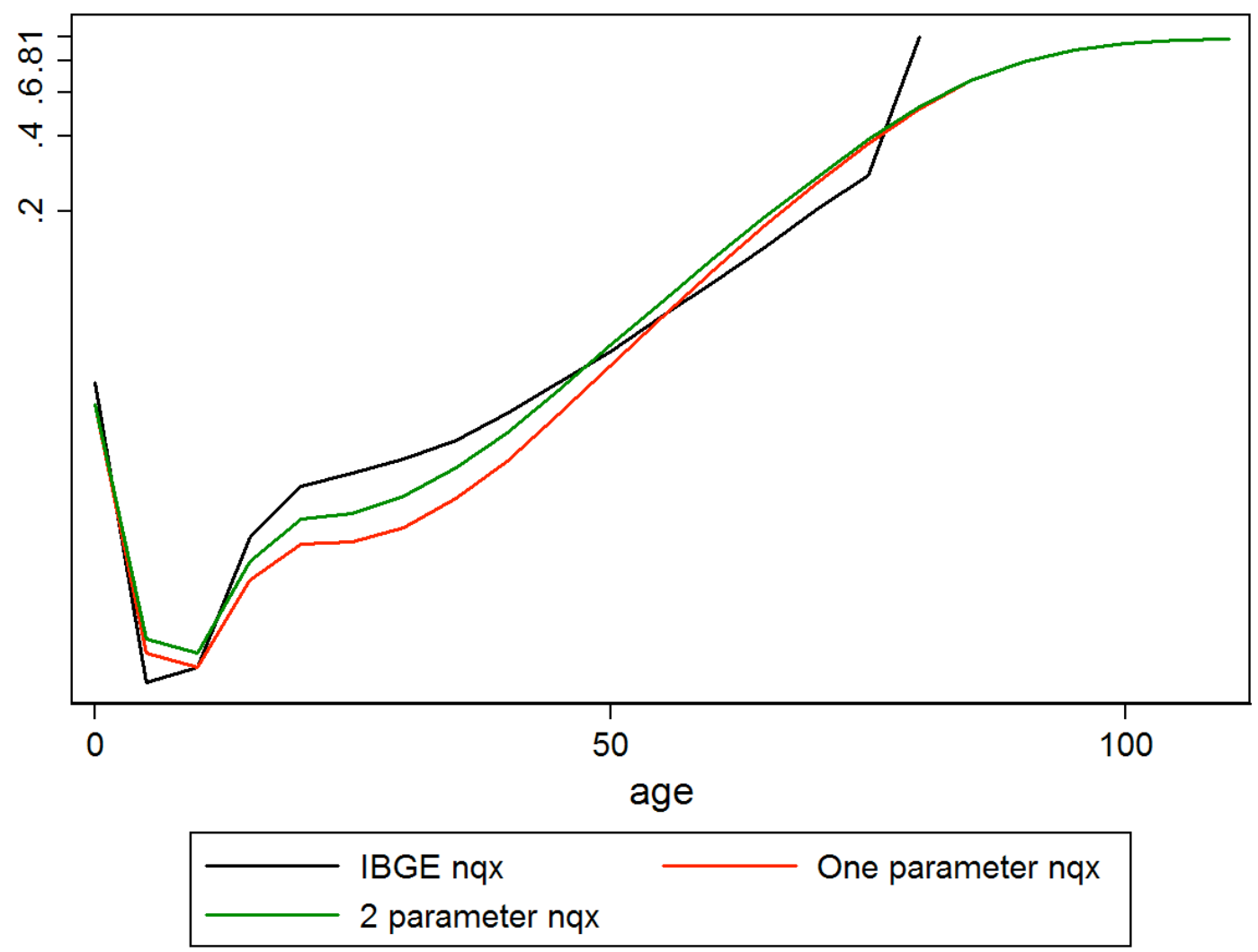

\subsection{Evolution of Death Counts by State Level in Brazil}

Figures 3 and 4 show the evolution of the registration of SIM-DATASUS mortality data between 1991-2000 and 2000-2010. The results show a considerable improvement of completeness of death counts coverage in Brazil and States (Agostinho and Queiroz, 2008; Queiroz, 2012; Lima and Queiroz, 2014). In almost all states in the Southeast and all southern states observed a complete coverage of adult mortality record, which did not occur in the previous intercensal period (1991-2000). Regarding the states in the Northeast and North, although there are still places with a low degree of coverage, for example Maranhao, there is a clear improvement compared to that observed between 1991-2000 (Agostinho and Queiroz, 2010).

Figure 3 - Completeness of Death Counts Coverage, average of Death Distribution Methods, Brazilian States, Males, 1980 to 2010. 


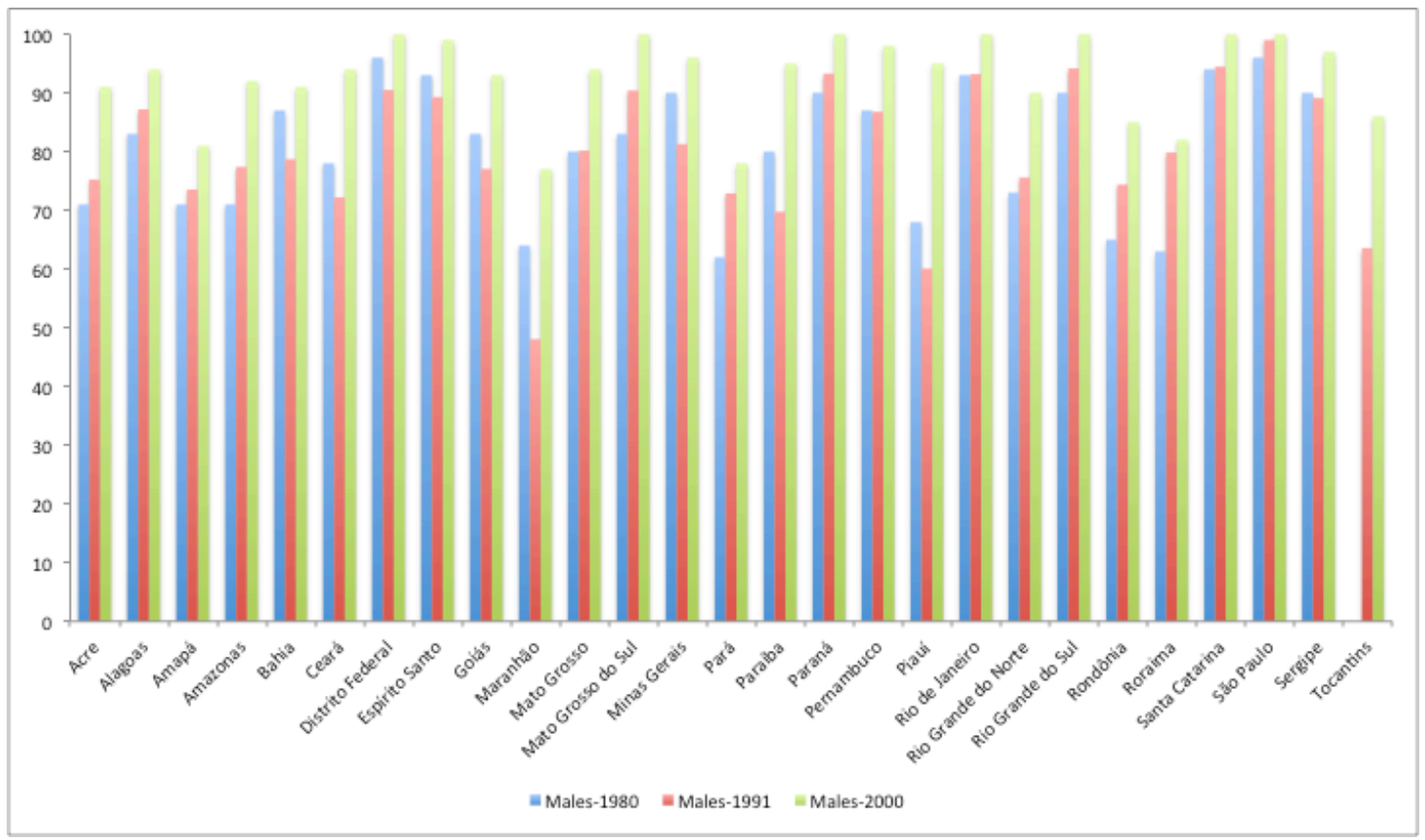

Figure 4 - Completeness of Death Counts Coverage, average of Death Distribution Methods, Brazilian States, Females, 1980 to 2010.

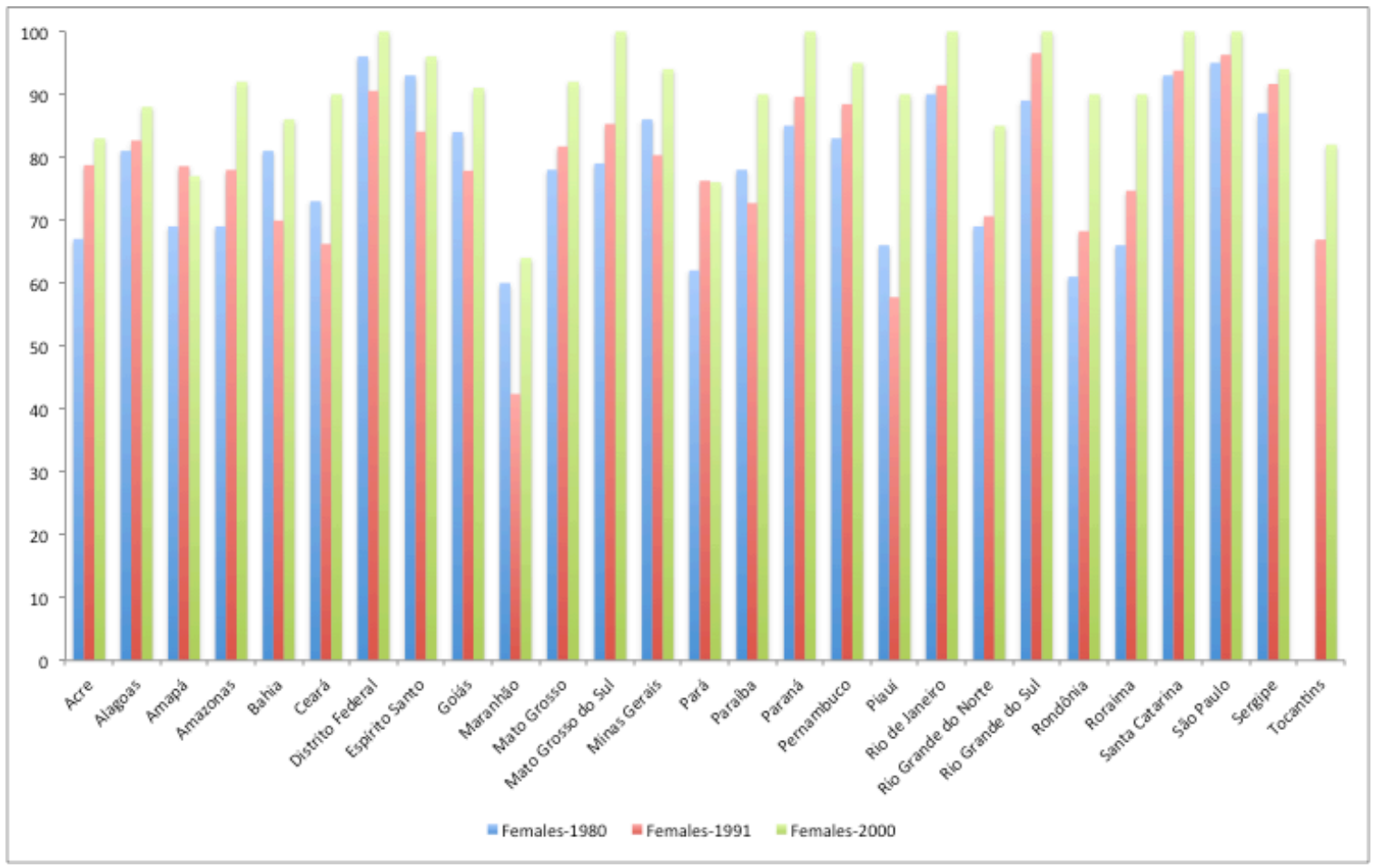

\subsubsection{Some comparative analysis with IHME - GBD for Brazil}


In our analysis, we evaluate the coverage of reported deaths we use traditional demographic methods, called Death Distribution Methods - DDM henceforth. In the case of IHME estimates, the criteria follows Murray, et. Al (2010): “On the basis of the three different validation datasets, we believe SEG 55-80, GGB 40-70, and GGBSEG 50-70 are the best methods that can be currently used to estimate relative completeness of death registration. The combination of the three optimal DDMs will yield much better results than the current practice of application of DDMs without optimal age trimming."

The main differences are in the 1970s and 1980s. IHME estimates almost complete death registration system for the country in those years, while we estimate an undercount of death records. 45q15 estimated by IHME for 1970s and 1980s are very close to values obtain directly from Datasus without any adjustment to the data. Combine with $5 \mathrm{q} 0$, those estimates will results in a very high life expectancy at birth. Our estimates, obtain the several papers cited below, are closer to what is used by the UN Population Division and estimates from IBGE - Brazilian National Statistics Office.

Table 3 - Adult Mortality Probabilities of Death, 45q15, Brazil - our estimates vs IHME, Males and Females, 1970-2010

\begin{tabular}{|c|c|c|c|c|c|c|c|c|}
\hline \multirow{2}{*}{$\begin{array}{c}\begin{array}{c}\text { Adult } \\
\text { Mortality }\end{array} \\
\mathbf{4 5 q 1 5}\end{array}$} & \multicolumn{4}{|c|}{ Males } & \multicolumn{4}{|c|}{ Females } \\
\hline & $1970-80$ & $\begin{array}{c}1980- \\
91\end{array}$ & $\begin{array}{c}\text { 1991- } \\
00\end{array}$ & $\begin{array}{c}2000- \\
10\end{array}$ & $\begin{array}{c}1970- \\
80\end{array}$ & $\begin{array}{c}1980- \\
91\end{array}$ & $\begin{array}{c}\text { 1991- } \\
00\end{array}$ & $\begin{array}{c}2000- \\
10\end{array}$ \\
\hline $\begin{array}{l}\text { Observed } \\
\text { Data } \\
\text { (Datasus } \\
\text { data) }\end{array}$ & 0,2466 & 0,2467 & 0,2242 & & 0,1430 & 0,1231 & 0,1116 & \\
\hline $\begin{array}{l}\text { Adjusted } \\
\text { Data (by } \\
\text { our } \\
\text { estimates) }\end{array}$ & 0,2861 & 0,2698 & 0,2354 & 0,2111 & 0,1774 & 0,1487 & 0,1223 & 0,1056 \\
\hline $\begin{array}{l}\text { IHME (got } \\
\text { results } \\
\text { from mid- } \\
\text { census } \\
\text { years) }\end{array}$ & 0.2539 & 0.2463 & 0.233 & 0.2044 & 0.1588 & 0.1335 & 0.1177 & 0.0998 \\
\hline
\end{tabular}

Figure 5 shows the trends in adult mortality for Brazil comparing estimates from the research group in Brazil to the estimates produced by IHME under the Global 
Burden of Diseases project. Levels of mortality estimated by IHME are always lower than obtain by our researcher group, for both males and females. More important, it seems that coverage level estimated by IHME differs in substantive magnitude from our estimates for the earlier period of analysis, for example, their estimates in the 1980's are higher than obtain using observed data from Datasus. More important, we see that estimates show a very different trend in the levels of adult mortality over the last three decades.

Figure 5 - Comparison between adult mortality estimates from IHME and our estimates using DDM, Brazil 1970-2010 (mid-census years)

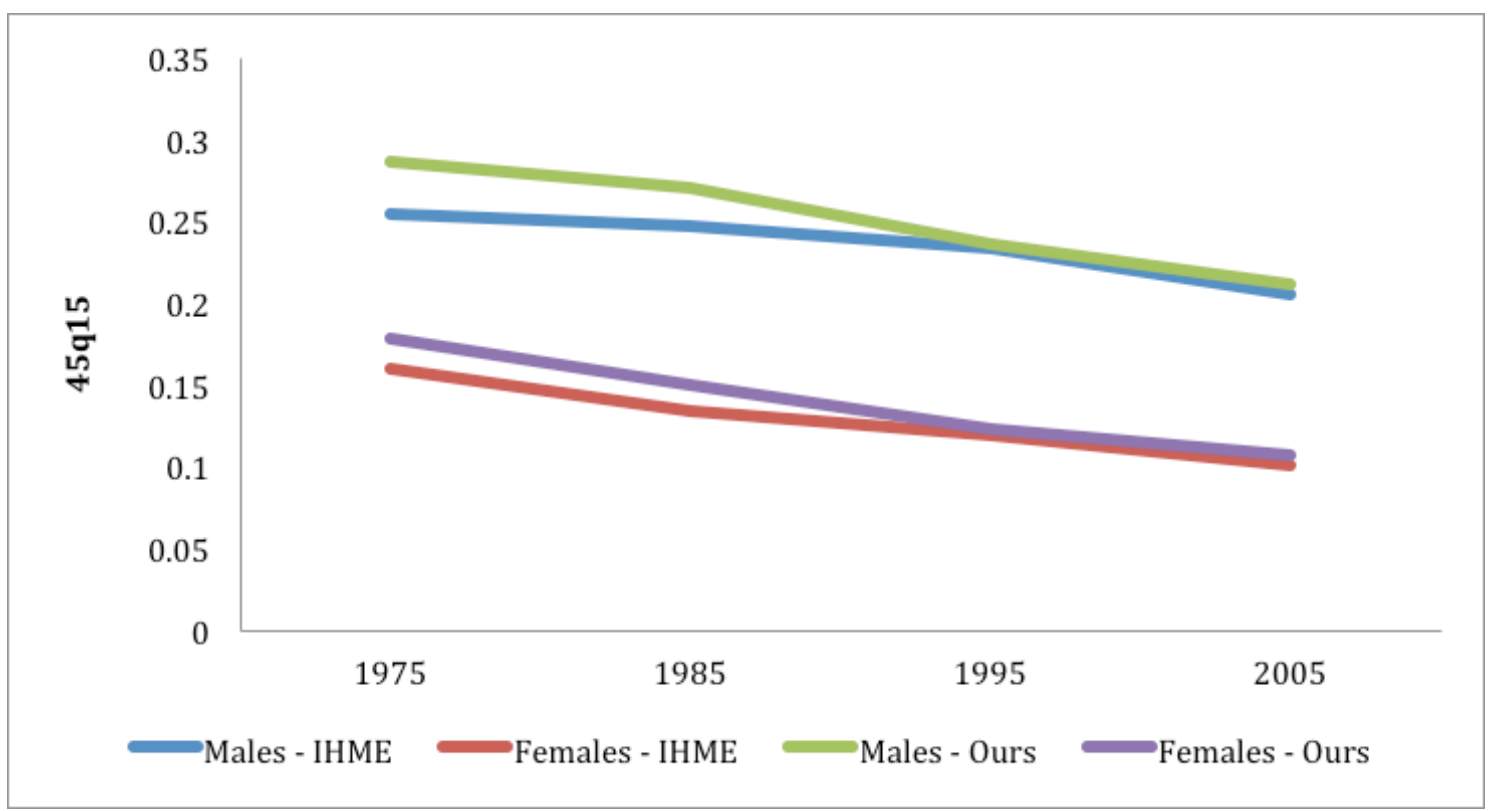

We also find signiticative differences at the state level. Our estimates indicate a faster decline in adult mortality from 1970 to 2010, contrary to what is observed in the IHME estimates. Figure 6 shows a comparison, for males in the most recent period, of adult mortality probabilities of death by our research group to the IHME estimates. We find differences even for states where data quality is considered to be of good quality such as regions in the Southeast parts of the country.

Figure 6 - Probabilities of Death Ages 15 to 60, 45q15, Males, Brazilian States, 20002010 


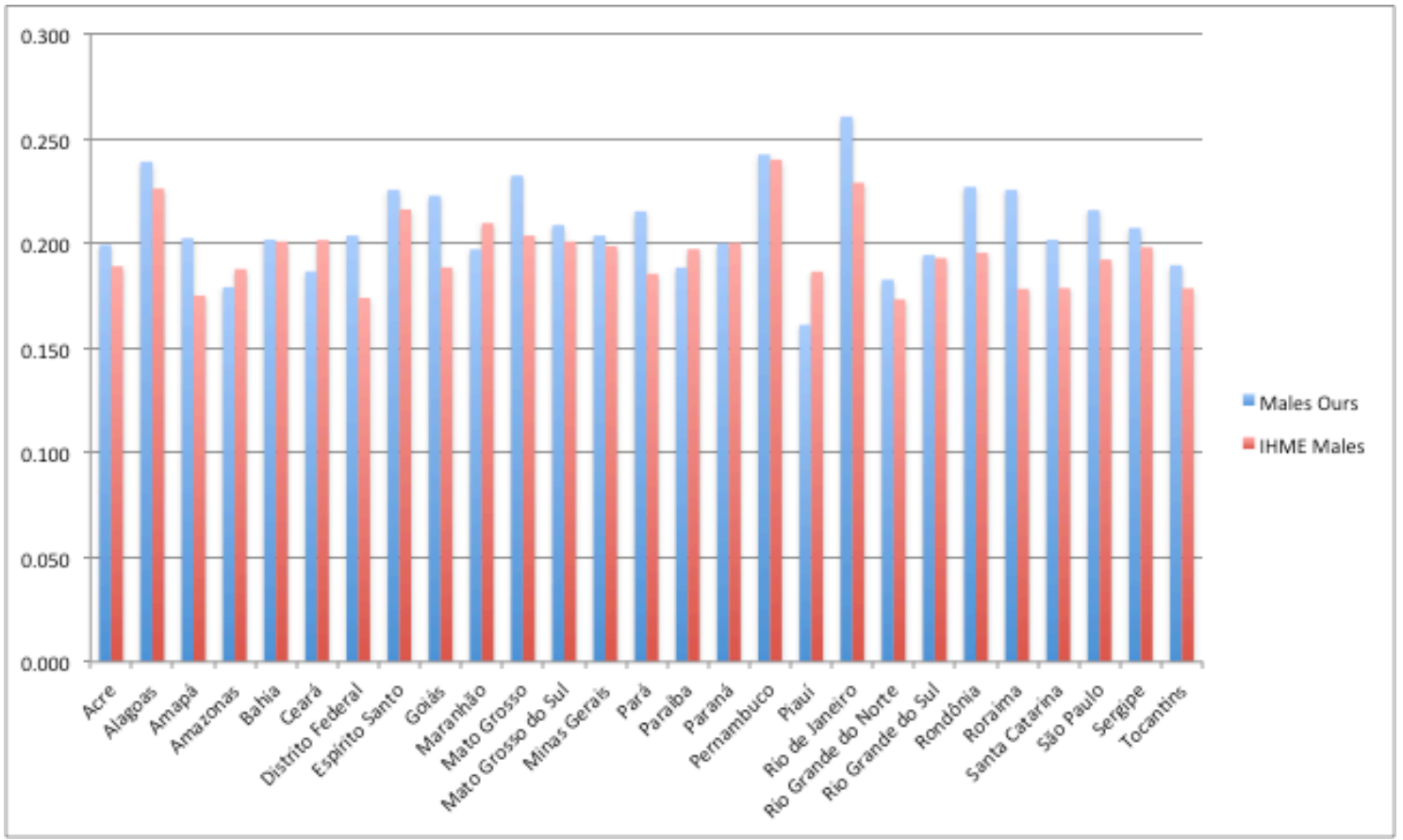

Figure 7 focuses on a brief comparison between two extreme states in Brazil, for the most recent period. We compare estimates for São Paulo, considered to have the best data quality in Brazil, to Maranhão, considered to have the worst data quality in Brazil. In Maranhão we estimate life expectancy at birth in 68.93 and IHME estimated in 68.54. For São Paulo, our estimates are 71.46 and theirs is 72.21 . These are pretty similar results, but when we compared ages-specific rates, some features are interesting to highlight.

Figure 7 - Age-Specific Mortality Rates, Males, Maranhão and São Paulo, 2010. 


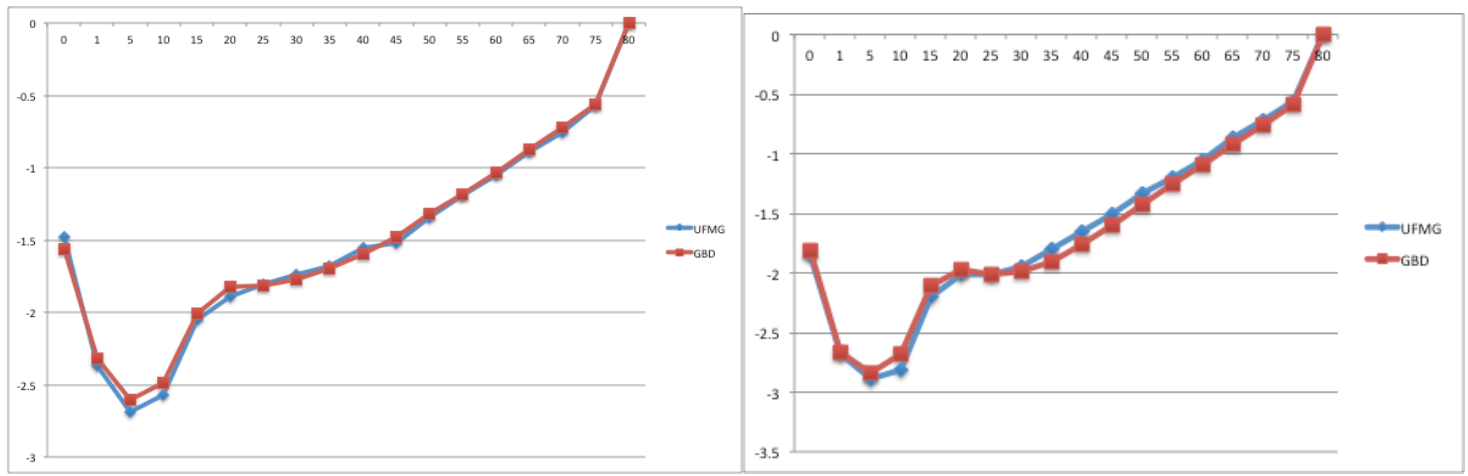

\subsection{Evolution of Death Counts Coverage by Small Areas}

In a recent paper, Queiroz, et.al (2016) ${ }^{2}$ estimated mortality levels for mesoregions in Brazil from 1980 to 2010. The paper uses three-step procedure to estimate mortality in small areas when data is defective. First, they apply a standardization technique to smooth rates in small areas. They standardize mortality rates from mesoregions (smaller areas), by sex, using state level data as standards Second, they obtained measures of completeness of death counts coverage through the Death Distribution Methods. Finally, we perform a bottom-up adjustment to make sure that adding up death counts at the local level we obtain the total number of deaths in each state and the country.

The original data is available at the municipality level. The main limitation in using city level data in Brazil is that the number and composition of cities change over time. In 1980, there were 3974 municipalities and in 2010 there were 5565. To avoid problems using this information, Queiroz and colleagues (2016) aggregated municipalities by comparable small areas, using the IBGE definition of comparable mesoregions. Mesoregions are stable and comparable over the period of analysis and it is possible to follow the same 137 regions from 1980 to 2010 (and more recent years).

Map 1 and Map 2, obtain from Queiroz and colleagues (2016), depicts the evolution of completeness of death counts in Brazil by sex and mesoregions from 1980 to 2010. We show before that completeness of death counts coverage is improving overtime in

\footnotetext{
${ }^{2}$ Work in in progress by the research group that BLQ and EECL are part. The paper is in final preparation to be submitted to a scientific journal. It is part of a larger research project on estimating mortality in small-areas in Brazil funded by CNPq. Results, data and codes are available upon request. A web-site will be released whenever the paper is accepted to publication.
} 
the country, but there are still significant regional variation. In the South and Southeast regions have better coverage of deaths counts than others regions in 1980 was over $90 \%$ reaching almost $100 \%$ in the more recent years. In the North and Northern parts of the country, completeness, is improving rapidly over the last decades (from $60 \%$ to $90 \%$ in the period).

Map 1 - Completeness of Death Counts Coverage, Males, Brazil, 1980-2010
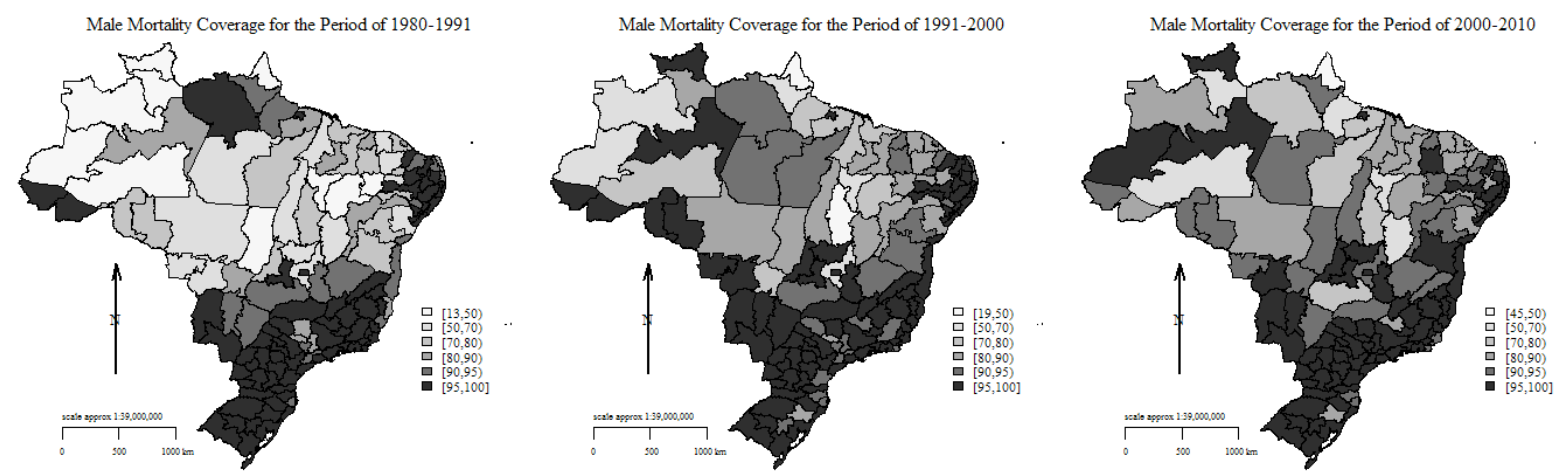

Source: Queiroz, et.al, (2016) 

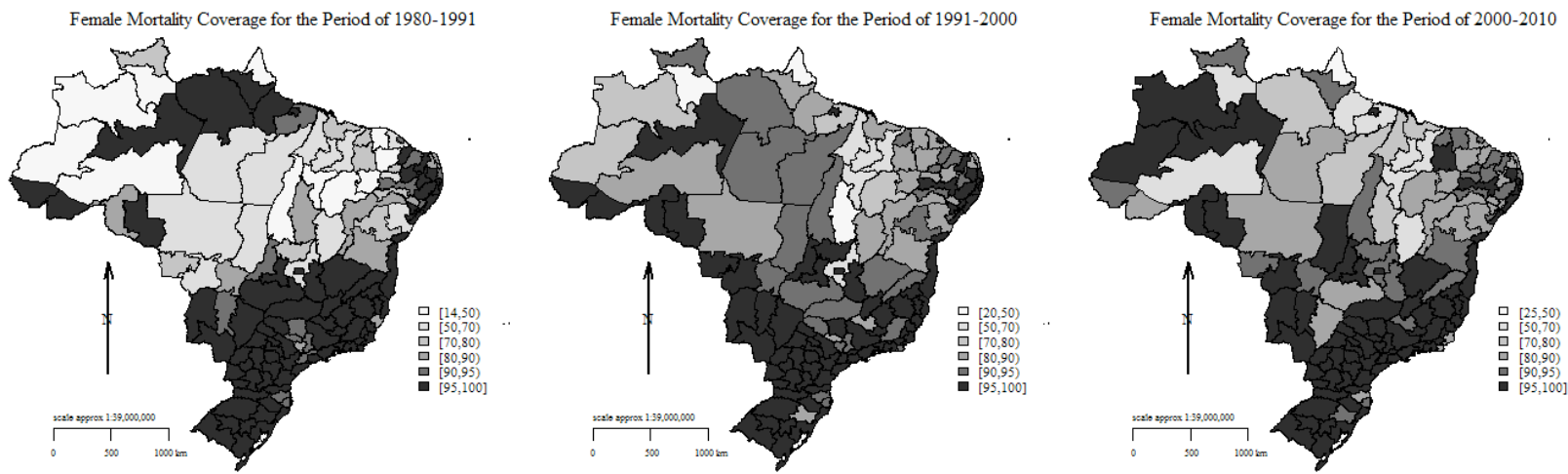

Source: Queiroz, et.al, (2016)

\subsection{Municipal Level Data: combining statistical methods to DDM}

We estimate mortality curves according to different parametric specifications. These models are used to fit the data when zero or few events are observed, which is the case in many age groups and municipalities. In addition to that, the models can smooth mortality functions for all municipalities in the period. To test these methods, we focus on two regions of the country: Maranhão, with 217 municipalities, and the State of São Paulo containing 645 municipalities. The choice of these two states is not random. Maranhão is well known for the worst quality of mortality data in the country while São Paulo presents better death count information. (Lima and Queiroz, 2014). Five models are estimated: three with a Poisson and two with a Negative Binomial specification

\section{a) Structure of mortality}

Figure 8 presents the mortality curves for selected municipalities from the two States in study. Results indicate that many municipalities have a series of zero cases of death in some age groups and very unstable mortality structure. We argue that this unstable mortality structure can result in untrustworthy measures of mortality, such as life expectancy and probabilities of death. The estimates using different methods are 
able to produce complete and smooth curves, however, a question that remains is which modelgives reliable estimates of mortalityin those small areas, and if those estimates are reasonable given the knowledge about the evolution of mortality in the country.

The curves estimated by the models do not vary in terms of structure, but they present different mortality levels, and visually the Poisson Hierarchical model (blue curve) is the one with closest distance ${ }^{3}$ from the observed values, cases of São Luís, Adamantina and São Paulo. In addition to that, this model is the only one where we can identify variation in the mortality levels. In general, the models do not fit infant and child mortality very well. This is a relevant point, we are working on different set of adjustments that will be presented in the final version of the paper. For this reason, we also evaluate the quality of the estimates generated bythe $45 \mathrm{q} 15$ (adult mortality). But, most important they are very useful to smooth mortality functions allowing to estimate life tables. In most cases, one cannot use observed data to perform any type of analysis.

Figure 8 - Parametric Models to Estimate Mortality Curves for Municipalities in Maranhão and São Paulo, Males, 2000
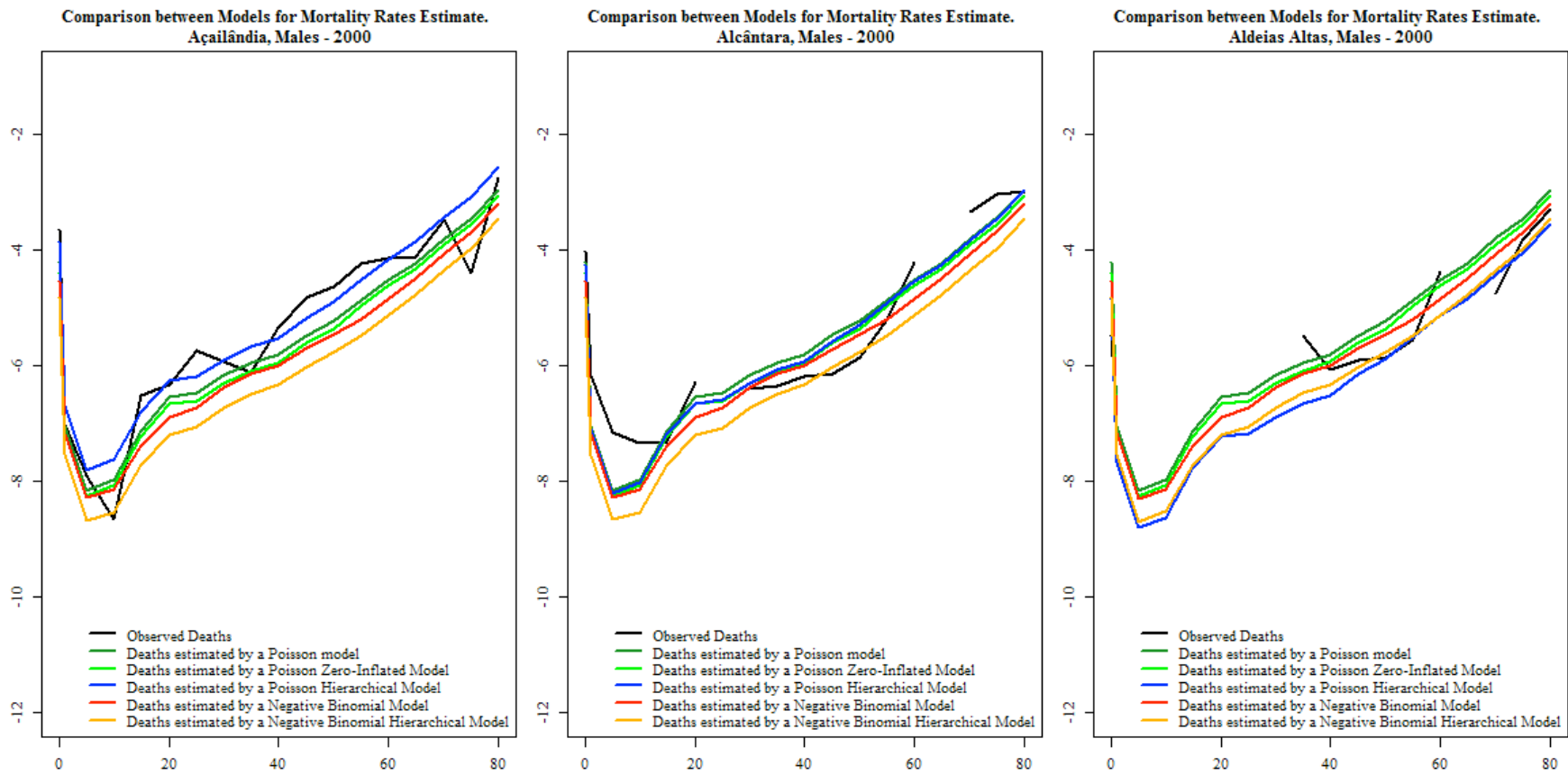

\footnotetext{
${ }^{3}$ The distances between observed and fitted curves was also estimated based on root mean square error (RMSE), which is a frequently used measure of the differences between values (sample and population values) predicted by a model or an estimator and the values actually observed.
} 

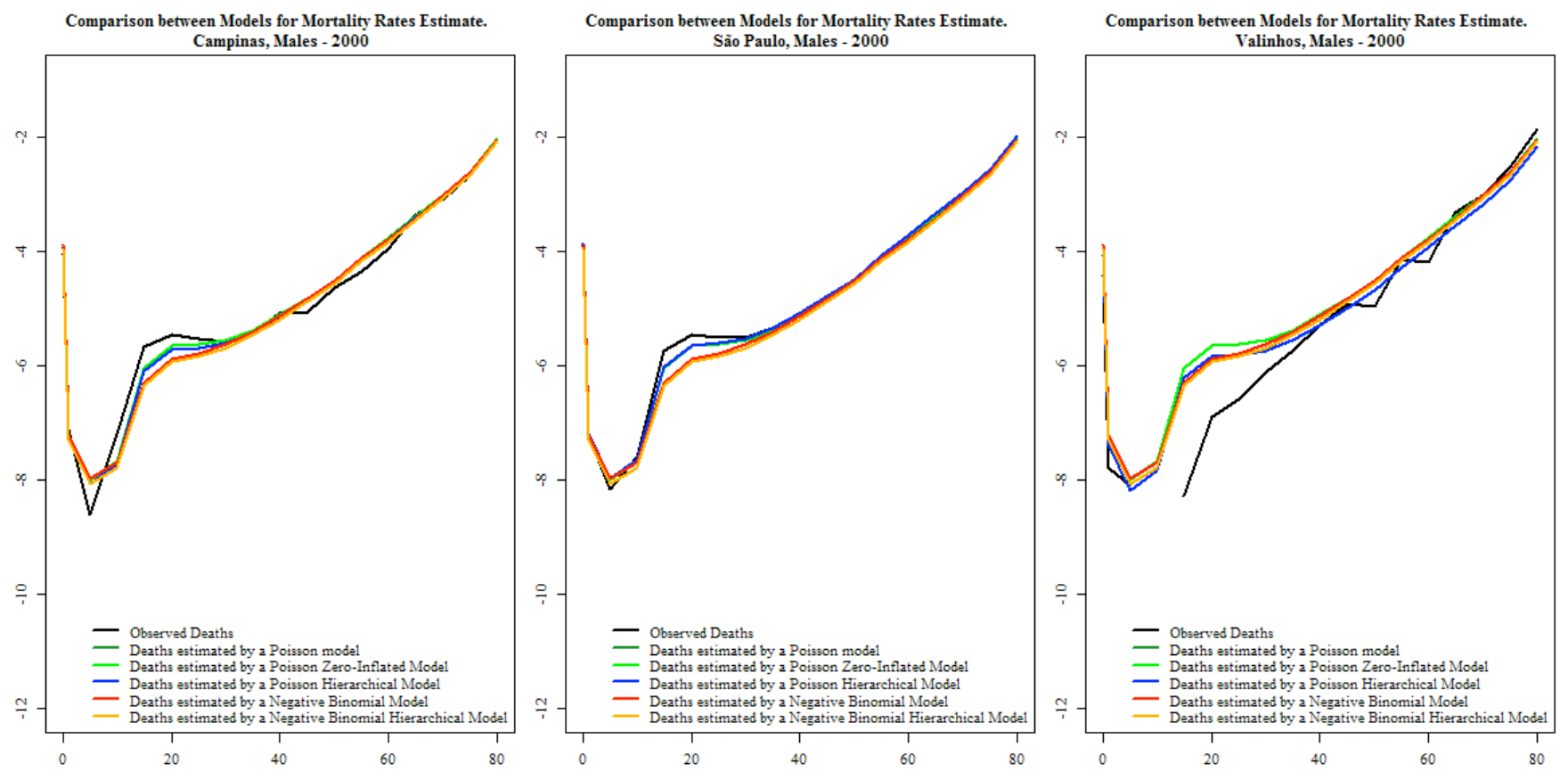

b) Mortality Levels

We use the estimate mortality age profiles to estimate number of death counts. From that, we apply Death Distribution Methods to evaluate quality of data and then reestimate the life expectancy for the 12 municipalities taken as example. The results indicate a significant reduction in mortality levels after we taken into account the degree of completeness of death counts. In the case of Aldeis Altas the life expectancy reduced in 16 years. The same picture is observed in other municipalities of Maranhão. 
Table 3: Life Expectancy estimated according to Poisson Hierarchical model

\begin{tabular}{lccc}
\hline Municipalities of Maranhão & Observed data & $\begin{array}{c}\text { Poisson } \\
\text { hierarchical } \\
\text { model }\end{array}$ & $\begin{array}{c}\text { Poisson hierarchical model } \\
\text { and correction for } \\
\text { mortality under- } \\
\text { registration all ages }\end{array}$ \\
\hline \hline Açailândia & 76.2 & 74.6 & 72.7 \\
Alcântara & 82.9 & 83.3 & 66.3 \\
AldeiasAltas & 95.6 & 101.2 & 79.6 \\
Alto Alegre do Pindaré & 91.1 & 82.2 & 74.9 \\
São Luís & 68.8 & 69.2 & 69.2 \\
ZéDoca & 80.2 & 80.6 & 74.4 \\
\hline & & & Poisson hierarchical model \\
and correction for \\
mortality under-
\end{tabular}

Source: Population Census (IBGE) and Datasus, 2000.

The results indicate that there is a major deficiency in the basic mortality data and population in small areas, which makes direct use of these sources problematic. Main limitations are the random variation due to small numbers in death counts by age and under-registration of death counts. Therefore, direct estimates of mortality levels in small areas could then produce results that are not robust, in other words, very high life expectancies at birth. In addition, application of demographic methods also appears to be limited, for the most localities, due to limitations of basic assumptions of the models. we attempt to test alternative parametric and non-parametric methods to estimate mortality curves by age in different municipalities of two states in Brazil, as an example. The proposed solutions, however, only solve the problems of zeros and unsmoothed rates. In most cases, we find that methods could be used to adult mortality, but not for infant and child mortality rates. 


\section{Discussion}

Adult mortality estimates for developing countries are less satisfactory than infant and child mortality estimates. There are two main reasons for that: there is not an equivalent to birth history to estimate child mortality from surveys and the methods used to estimate adult mortality from surveys are less robust than the ones used to estimate infant and child mortality. In result, we know much less about level and trends of adult mortality in developing countries than what we know about infant and child mortality.

The results about the evolution of completeness of death counts and adult mortality in Brazil show us remarkable regional differences on the completeness of deaths counts and adult mortality across three last decades. For both sex the North and Northeast Brazil had more improvement on the completeness of deaths counts during the last three decades. Areas closest of the states' capitals have higher coverage during all the period on both regions. Estimations of infant deaths coverage using a procedure called Active Search on the Northeast and Amazon regions (Szwarcwald et al, 2011) showed that the deaths under-reporting on those areas should be lower than the official estimates (IBGE, 2016).

In this paper we find that:

1. Quality of death counts registration in Brazil is improving over time and across the country;

2. However, there is a wide regional variation. We find regions with complete records in the South and Southeast parts of the countries and some regions in the North and Northeast parts with very low levels of completeness.

3. There is a close association with development level

4. Quality of female registration is lower than for males, and this should be a point of analysis

5. Methods and combination of methods work well for sub-national levels. Results from 1980 to 2010 for meso-regions are very promising even using traditional demographic methods

6. Combination of methods and combination of demographic and statistical methods are very promising, but one should be careful with migration and small number issues; 
The observed improvements seem to be very close associated to investments in the public health care system and administrative procedures to collect vital statistics (França, et.al, 2008; França, et.al, 2011). Thus, the quality of mortality data for adults seems to have expressively improved through the years and across many regions. At the same time, we find that in areas where mortality is concentrated at older ages the percentage of deaths registered as ill-defined also increase.

The main limitation is the application of the death distribution methods for small areas. The methods make strong assumptions about closed population and constant quality of declaration across age that is more limited for smaller areas. We believe that this is an important area of future research. In this paper, we have followed similar approach performed by others and we considered them to be reasonable based on the relative pattern of completeness across regions. Despite these limitations, we believe that the study gives important insights about the evolution of data quality in Brazil and indicates that the South, Southeast and Mid-West regions have good mortality data and the North and Northeast are improving consistently in recent years.

The analysis suggests that efforts from the central and local governments to improve data quality in Brazil are being successful, and they will allow a better understanding of the dynamics of health and mortality transition in Brazil. Continuous investments in the Brazilian Family Health Program could have important impacts on the improvement of mortality data quality in Brazil since its personnel works closely to the community and follows the health status of several individuals under their jurisdiction.

\section{References}

AbouZahr, Carla, Don De Savigny, Lene Mikkelsen, Philip W. Setel, Rafael Lozano, and Alan D. Lopez. "Towards universal civil registration and vital statistics systems: the time is now." The Lancet 386, no. 10001 (2015): 1407-1418.

Agostinho, C. S., \& Queiroz, B. L. (2008). Estimativas da mortalidade adulta para o Brasil no período 1980/2000: uma abordagem metodológica comparativa. Anais do XVI Encontro Nacional da ABEP.

Assunção, R. M.; Schmertmann, C. P.; Potter, J. E.; Cavenaghi, S. M. (2005).Empirical Bayes Estimation of Demographic Schedules for Small Areas.Demography, Vol. 42, No. 3, (Aug., 2005), pp. 537-558. 
United Nations Expert Group Meeting : "Methodology and lessons learned to evaluate the completeness and quality of vital statistics data from civil registration"

Bernardinelli, L. and Montomoli, C. (1992). Empirical Bayes versus fully Bayesian analysis of geographical variation in disease risk.Statistics in Medicine, 11: 983-1007.

Banister, J; Hill, K. Mortality in China 1964-2000. Population Studies, 2004, v. 58, n. 1, p.5575

Bennett, NG;Horiuchi, S. (1981) Estimating the Completeness of Death Registration in a Closed Population. Population Index 47(2):207-21.

Bhat, Mi. (2002). General growth balance method: a reformulation for populations open to migration. Population Studies, 56, 23-34

Brass, W. (1964) Uses of census or survey data for the estimation of vital rates" (E/CN.14/CAS.4/V57), Paper prepared for the African Seminar on Vital Statistics, Addis Abbaba . 14-19 December.

Brass, W. (1975). Methods for Estimating Fertility and Mortality from Limited and Defective Data. Chapel Hill, N.C: International Programme of Laboratories for Population Statistics, North Carolina Population Center, 1975.

Castro, M.C; Simoes, C.C.S. (2009). Spatio-Temporal Trends of Infant Mortality inBrazil. Paper presented at the XXVI IUSSP International Population Conference,Marocco.

Dorrington R.E. General Growth Balance. In Moultrie TA, RE Dorrington, AG Hill, KH Hill, IM Timæus and B Zaba (eds), Tools for Demographic Estimation. http://demographicestimation.iussp.org/content/general-growth-balance, 2011

Dorrington R.E. Synthetic extinct generations. In Moultrie TA, RE Dorrington, AG Hill, KH Hill, IM Timæus and B Zaba (eds), Tools for Demographic Estimation. http://demographicestimation.iussp.org/content/synthetic-extinct-generations, 2011

Dorrington, R e Timaeus, I. Death Distribution Methods for Estimating Adult Mortality: Sensitivity Analysis with Simulated Data Errors, Revisited. Paper presented at the 2008 Annual Meeting of the Population Association of America - Nova Orleans, Estados Unidos., 2008

Dorrington, R., Timaeus, I., Gregson, S. Adult Mortality in Southern Africa using Deaths reported by households: some methodological issues and results. Meeting of the Union for African Population Studies, 2007.

Ferguson, B.; Reniers, G.; Araya, T.; Jones, J. H.; Sanders, E. (2004) Empirical Bayes Estimationof Small Area Adult Mortality Risk in Addis Ababa, Ethiopia. In: Annual Meeting of the Population of Association of America - 2004. Boston, Massachusetts, April 1-3.

França E, Campos D, Souza MF. Use of verbal autopsy in a national health information system: Effects of the investigation of ill-defined causes of death on proportional mortality due to injury in small municipalities in Brazil. Population Health Metrics. 2011; 9: 39.

França EB, Abreu DMX, Rao C, Lopez A. Evaluation of cause-of-death statistics for Brazil, 2002 2004. International Journal of Epidemiology. 2008; 37:891-901. 
United Nations Expert Group Meeting : "Methodology and lessons learned to evaluate the completeness and quality of vital statistics data from civil registration"

Hill, K. (1987). "Estimating census and death registration completeness." Asian and Pacific Census Forum, 1(3): 8-13,23-24.

Hill, K. (2000). Methods for Measuring Adult Mortality in Developing Countries: A Comparative Review. The Global Burden of Disease in Aging Populations - Research Paper No. 01.13.

Hill, K. (2003). Metodos para estimar la mortalidad adulta en los paises en desarollo: una revision comparativa. Notas de Poblacion, no. 76 pps. 81-111.

Hill, K., \& Queiroz, B. (2010). Adjusting the general growth balance method for migration. Revista Brasileira de Estudos de População, 27(1), 7-20.

Hill, K; Choi, Y; Timaeus, I. (2005). Unconventional approaches to mortality estimation. Demographic Research, v.13, p.281-300.

Hill, K; You, D; Choi, Y. (2009).Death Distribution Methods for Estimating Adult Mortality: sensitivity analysis with simulated data errors Demographic Research, vol 21, 2009.

IBGE. Tábuas Abreviadas de mortalidade por sexo e idade: Brasil, Grandes Regiões e Unidades da Federação, 2010. Estudos e pesquisas. Informação Demográfica e Socioeconômica, n. 30. Rio de Janeiro: 2013. ABGE, Avaliable at: http://ibge.gov.br/home/estatistica/populacao/tabuas_abreviadas_mortalidade/2010/default.shtm . Access at: 07/07/2016.

Johnson, L. F., Dorrington, R. E., Laubscher, R., Hoffmann, C. J., Wood, R., Fox, M. P., ... \& Davies, M. A. (2015). A comparison of death recording by health centres and civil registration in South Africans receiving antiretroviral treatment. Journal of the International AIDS Society, $18(1)$.

Lima, E. E. C. D., \& Queiroz, B. L. (2014). Evolution of the deaths registry system in Brazil: associations with changes in the mortality profile, under-registration of death counts, and illdefined causes of death. Cadernos de Saúde Pública, 30(8), 1721-1730.

Lima, E; Queiroz, B. Missov, T. Lenart, A. Reconstructing mortality in Brazilian municipalities: methods, limitations, and examples. Paper presented at the 2016 European Conference.

Lima, E. E. C.; Queiroz, B. L.. A evolução do sub-registro de mortes e causas de óbitos mal definidas em Minas Gerais: diferenciais regionais. Revista Brasileira de Estudos de População, Rio de Janeiro, v. 28, n. 2, p. 303-320, jul./dez. 2011.

Lima, E. E. C. D., Queiroz, B. L., \& Sawyer, D. O. (2014). Estimating death counts completeness and mortality in small areas: an application to Minas Gerais microregions. Cadernos Saúde Coletiva, 22(4), 409-418.

Luy, M. (2010). A Classification of the Nature of Mortality Data Underlying the Estimates for the 2004 and 2006 United Nations' World Population Prospects. Comparative Population Studies, vol. 35, no. 2, 2010. 
Mathers,CD; Inoue, M; Rao, C; Lopez, AD. (2005). Counting the dead and what they died from: an assessment of the global status of cause of death data. Bulletin of the Word Health Organization 83(3), March: 171-9.

Ministério da Saúde. Sistema de Informações sobre Mortalidade (SIM) de 1979 a 2010.

Ministério da Saúde. Health surveillance in SUS: strengthening the responsiveness for old and new challenges. [Vigilância em saúde no SUS: fortalecendo a capacidade de resposta para velhos e novos desafios]. Brasília: MS; 2006:43-7. Available from: http://bvsms.saude.gov.br/bvs/publicacoes/vigilancia_saude_SUS.pdf

Mahapatra P, Shibuya K, Lopez AD, Coullare F, Notzon FC, et al. (2007) Civil registration systems and vital statistics: successes and missed opportunities. Lancet 370: 1653-1663

Murray, CJL; Rajaratnam JK, Marcus J, Laakso T, Lopez AD. What can we conclude from death registration? Improved methods for evaluating completeness. PLoS Medicine. 2010 April $13 ; 7(4)$

Paes, N. A. Avaliação da cobertura dos registros de óbitos dos Estados brasileiros em 2000. Revista de Saúde Pública, USP, v. 39 n.6, p. 882-90, 2005.

Paes, N. A.; ALBUQUERQUE, M. E. E. Avaliação da qualidade dos dados populacionais e cobertura dos registros de óbitos para as regiões brasileiras. Revista de SaúdePública, USP, v. 33, n. 1, p. 33-43, 1999.

Preston, Samuel, HEUVELINE, P. and GUILLOT, Michel. Demography: Measuring and Modeling Population Processes. Oxford: Blackwell, 2001.

Queiroz, B.L., Lima, E.; Freire, F; Gonzaga, M. (2016) “Temporal and spatial estimates of adult mortality for small areas in Brazil, 1980-2010". Working Paper in preparation for submission.

Queiroz, B. L., \& Sawyer, D. O. (2012). O que os dados de mortalidade do Censo de 2010 podem nos dizer. Rev Bras Estud Popul, 29, 225-38.

Queiroz, B. L. (2012). Estimativas do Grau de Cobertura e da Esperança de Vida para as Unidades da Federação no Brasil entre 2000 e 2010. XVIII Encontro de Estudos de População da ABEP, realizado em Águas de Lindóia, São Paulo, entre, 19.

Sawyer DO, Castilla FM. Dados, medidas e técnicas indiretas de estimação da mortalidade. Rev Bras Estud Popul 1989; 6:39-61

Sawyer, D. O.. A qualidade dos dados e as estimativas de mortalidade em algumas áreas brasileiras In: VI ENCONTRO NACIONAL DE ESTUDOS POPULACIONAIS, 1988, Olinda. Anais do VI Encontro Nacional de Estudos Populacionais. São Paulo: ABEP, 1988. v. 4. p. 301324.

Setel P, MacFarlane SB, Szreter S, Mikkelsen L, Jha P, et al. (2007) Who Counts (1): A scandal of invisibility: making everyone count by counting everyone. Lancet 370: 1569-1577. 
United Nations Expert Group Meeting : "Methodology and lessons learned to evaluate the completeness and quality of vital statistics data from civil registration"

Silva, Lariça Emiliano da, Flávio Henrique Miranda de Araújo Freire, and Rafael Henrique Moraes Pereira. "Diferenciais de mortalidade por escolaridade da população adulta brasileira, em 2010." Cadernos de Saúde Pública 32, no. 4 (2016).

Timaeus, I. M. Measurement of adult mortality in less developed countries: A comparative review. Population Index, v.57, n.4, p.552-568, 1991

United Nations. Principles and Recommendations for Population and Housing Censuses. Statistics Division, Department of Economic and Social Affairs.

ST/ESA/STAT/SER.M/67?Rev.2. New York, 2007

United Nations - Population Division. Methods for Estimating Adult Mortality. New York, 2002

Wilmoth, J.; Zureick, S.; Canudas-Romo, V.; Inoue, M.; Sawyer, C. (2012). A flexible twodimensional mortality model for use in indirect estimation. Population Studies, 66(1): 1-28.

Zlotnik H and Hill KH. (1981). "The Use of Hypothetical Cohorts in Estimating Demographic Parameters Under Conditions of Changing Fertility and Mortality." Demography 18(1):103-22. 